\title{
Caries experience in young children with congenital heart disease in a developing country
}

\section{Elizangela Lins Cavalcanti Pimentel(a) \\ Vitor Manuel Pereira Azevedo(a) \\ Rodolfo de Almeida Lima Castro(b) \\ Luciana Carvalho Reis ${ }^{(a)}$ \\ Andrea De Lorenzo(a)}

(a) Education and Research Department, Instituto Nacional de Cardiologia - INC, Rio de Janeiro, RJ, Brazil.

(b) Department of Nutrition in Public Health, Nutrition School, Univ Federal do Estado do Rio de Janeiro - Unirio, Rio de Janeiro, RJ, Brazil.
Declaration of Interests: The authors certify that they have no commercial or associative interest that represents a conflict of interest in connection with the manuscript.

\section{Corresponding author:}

Elizangela Lins Cavalcanti Pimentel

E-mail: elcpimentel@superig.com.br

Submitted: Aug 25, 2012

Accepted for publication: Jan 12, 2013

Last revision: Jan 27, 2013

\begin{abstract}
Oral care is frequently suboptimal in children from developing countries, especially those suffering from severe systemic diseases. The aim of the present study was to analyze the oral epidemiological profile of 3-to-5-year-old children with congenital heart disease. Dental and medical records of children evaluated at the Dental Service of the National Institute of Cardiology, Rio de Janeiro, Brazil, were reviewed. Caries experience was reported using the $\mathrm{dmft}$ index. Negative behavior towards dental management was recorded. The sample consisted of 144 children aged $4.41 \pm 0.95$ years. The mean dmft value was $5.4 \pm 4.9$, and $80.5 \%$ had at least one caries lesion. Dmft index was greater in the presence of cyanotic cardiac disease and in children with negative behavior. An increase in the "missing" component of the dmft index was also found in children using medicine on a daily basis. A higher caries experience was associated with children whose fathers had only an elementary education. In conclusion, children with congenital heart disease had high levels of caries experience at a young age. Cyanosis, negative behavior, daily use of medicine, one-parent family and the educational level of fathers seem to influence caries experience in children with congenital cardiac disease.
\end{abstract}

Descriptors: Child; Heart Defects, Congenital; Dental Caries; Dentistry.

\section{Introduction}

Heart disease is one of the most common developmental abnormalities among children, occurring in approximately 8 to 10 in 1,000 births. ${ }^{1}$ Dental management of children with congenital heart disease requires special attention, because of their heightened susceptibility to infectious endocarditis, associated with bacteremia induced by invasive dental procedures. Furthermore, these patients commonly have developmental enamel defects that increase caries risk, and often have poor oral health. ${ }^{2-4}$ The latter condition may be largely attributed to cardiac disease, whose attention and care may cause oral health to be underestimated and not be given due importance. ${ }^{2,4}$ In addition, the chronic administration of liquid medicines sweetened with sucrose may increase the incidence of caries and gingivitis in children. ${ }^{2,5}$ Dental disease may lead to dental extractions in young children, possibly requiring general anesthesia, thus compounding the problem with additional financial, 
emotional and physical burdens. ${ }^{6}$

Hallet et al. ${ }^{2}$ compared the oral health of children suffering from congenital heart disease with that of children from healthy controls, and found that the incidence of caries lesions was significantly higher in the former group. Moreover, parents of these children were not often aware of the need to prevent dental infections. On the other hand, some studies have shown that awareness alone toward the importance of good oral health does not necessarily lead to appropriate daily oral care. ${ }^{4,7}$ Franco et al. ${ }^{7}$ found a significant increase in the number of permanent teeth with untreated caries in children with heart disease, compared to controls. They suggested that negative behavior regarding dental management could at least be partially responsible for the difficulty to treat these children.

In a recent study, Balmer et al. ${ }^{8}$ found no significant differences between the oral health of children considered at a very high risk for infective endocarditis and healthy children, although the caries scores of the study group were high. The proportion of children with untreated caries, despite good dental awareness and attendance, was of concern. Another recent study reported a low caries index and no statistical difference when comparing young congenital heart disease patients with healthy controls. ${ }^{6}$ The data from this study group showed that the test group had a reduced oral health-related quality of life in some specific domains, including family stress and psychological impact on the child. ${ }^{6}$

Current evidence from animal models suggests that bacteremia leading to infective endocarditis may be induced by routine situations, such as oral hygiene and chewing. ${ }^{9}, 10$ However, Hartzell et al. ${ }^{11}$ reported that patients with satisfactory oral health (without gingival bleeding) did not show bacteremia during toothbrushing. This reinforces the importance of taking preventive measures and giving periodic information to patients and their parents about the risk of infective endocarditis and the need to maintain good oral health. Recommendations on antibiotic prophylaxis against infective endocarditis have changed dramatically over the past ten years, ${ }^{9,10,12}$ and the relationship between a patient's dentition and overall systemic health has been studied extensively. ${ }^{13}$ The inclusion of a preoperative dental examination has been used effectively in surgical procedures, ${ }^{13}$ but little data are available on the oral health of children with congenital heart disease, especially those from a developing country.

The interest in identifying caries-risk individuals has increased, moreover because of the heterogeneous epidemiological distribution of dental caries. ${ }^{14}$ Accordingly, this paper proposed to study the oral epidemiological profile of young children from a developing country, who suffer from congenital heart disease, and also to investigate the possible associations between oral health status and social, medical and behavioral variables.

\section{Methodology}

The dental and medical records of children aged 3 to 5 years, with congenital heart disease, evaluated at the Dental Service of the National Institute of Cardiology (Brazil) from December 2000 to March 2011, were reviewed by a pediatric dentist. The research protocol was approved by local ethics review board under number CAAE 0002.0.185.000-07. Children were included when medical and dental records were completely filled out.

The data collected included demographic data (age, gender and parent's age), data on social and behavioral variants (parent's education level, oneparent family, breastfeeding, behavioral problems in dental management, treatment refusal by another dentist), medical history (presence of cyanotic cardiac disease, infective endocarditis prophylaxis indication, daily use of medicine and preoperative status), data on parents' awareness of cardiac disease, dental health, and the importance of infective endocarditis antibiotic prophylaxis and its purpose. The recommendations from the American Heart Association were followed in determining the need for endocarditis prophylaxis. ${ }^{9}$

Oral examination data were collected and the caries experience was reported using the World Health Organization (WHO) criteria for deciduous teeth, i.e. the dmft (the sum of decayed teeth, teeth missing because of caries, and filled teeth) index..$^{15}$ This information is always collected at the child's first visit to a dental service. 
The type of behavior towards dental management was classified according to Frankl's definition (definitely negative, negative, positive, and definitely positive). ${ }^{16}$ For the purpose of this study, definitely negative and negative patterns were analyzed together, and described as negative behavior.

\section{Statistical analysis}

Continuous variables were expressed by means \pm standard deviation or median, and by the interquartile interval when appropriate, whereas categorical variables were expressed in percentages and with a $95 \%$ confidence interval. Student's t test or the chi-square test was used to investigate differences between the groups. The Mann-Witney test was used in the case of abnormal distribution of continuous variables. The Statistica 8.0 (StatSoft Inc., Tulsa, USA) software package was used for all analyses, and a pvalue $<0.05$ was considered statistically significant.

\section{Results}

One hundred and forty four children were studied. The mean age was $4.41 \pm 0.95$ years, and $52.1 \%$ were boys. Table 1 shows the children's medical history. Note that a high proportion of the patients were indicated for cardiac surgery, and many were considered at a high risk for infective endocarditis.

The age of the patients' parents was $31.5 \pm 7.8$ years for mothers and $33.5 \pm 7.7$ years for fathers. The educational level for mothers was elementary school: $52.8 \%$, high school: $37.5 \%$, and university: $3.5 \%$. For fathers, it was $45.8 \%, 27.8 \%$, and $0.0 \%$, respectively. There is no information on the educational level of $6.2 \%$ of mothers and $26.4 \%$ of fathers. The presence of a father in the children's life was observed in $85.4 \%$ of the youngsters.

Table 1 - Children's medical history.

\begin{tabular}{l|r|c}
\hline & $\mathrm{n}(\%)$ & $95 \% \mathrm{Cl}$ \\
\hline Daily use of medicine & $91 / 144(63.2)$ & $54.7-70.9$ \\
\hline Cyanotic cardiac disease & $61 / 144(42.4)$ & $34.3-50.9$ \\
\hline Preoperative status & $135 / 144(93.7)$ & $88.1-96.9$ \\
\hline Risk for infective endocarditis & $126 / 144(87.5)$ & $84.2-94.7$ \\
\hline
\end{tabular}

$\mathrm{Cl}$ : confidence interval
Table 2 displays parents' oral-health-related behavioral aspects and their awareness of the association between oral health and cardiac disease, including predisposition to infective endocarditis and likelihood of an antibiotic prophylaxis. Table 3 correlates the mean $\mathrm{dmtf}$ index of children with congenital heart disease and the educational level of their parents, separated into two groups,

1. high school/university and

2. elementary/no education.

There was a significant association between a higher caries index and a lower educational level of fathers.

Table 2 - Breastfeeding, dentist's refusal and awareness of dental and cardiac disease.

\begin{tabular}{|c|c|c|}
\hline & n (\%) & $95 \% \mathrm{Cl}$ \\
\hline Breastfeeding & $119 / 144(82.6 \%)$ & $75.2-88.2$ \\
\hline $\begin{array}{l}\text { None or breastfeeding } \leq 6 \\
\text { months }\end{array}$ & 79/144 (54.9\%) & $46.0-62.8$ \\
\hline $\begin{array}{l}\text { Breastfeeding }>6 \\
\text { months } \leq 1 \text { year }\end{array}$ & $32 / 144(22.2 \%)$ & $16.0-30.2$ \\
\hline Breastfeeding $>1$ year & $33 / 144(22.9 \%)$ & $16.6-31.0$ \\
\hline $\begin{array}{l}\text { Refusal of dental treatment } \\
\text { by another dentist }\end{array}$ & $31 / 144(21.5 \%)$ & $15.3-29.3$ \\
\hline \multicolumn{3}{|l|}{ Awareness of: } \\
\hline $\begin{array}{l}\text { relation between oral health } \\
\text { and cardiac disease }\end{array}$ & $95 / 144(66.0 \%)$ & $57.6-73.6$ \\
\hline $\begin{array}{l}\text { need for antibiotic } \\
\text { prophylaxis }\end{array}$ & $74 / 144(51.4 \%)$ & $43.0-59.7$ \\
\hline $\begin{array}{l}\text { purpose of antibiotic } \\
\text { prophylaxis }\end{array}$ & 29/144 (20.1\%) & $14.1-27.8$ \\
\hline
\end{tabular}

$\mathrm{Cl}$ : confidence interval.

Table 3 - Relationship between mean dmft index and parents' educational level.

\begin{tabular}{l|c|c|c|c|}
\hline & \multicolumn{3}{|c}{ dmft index } \\
\cline { 2 - 4 } & Median & Q 25 & Q 75 & p value \\
\hline Mother & 5.5 & 2.0 & 8.5 & \multirow{2}{*}{0.1782} \\
\hline Elementary/no education & 4.0 & 0.0 & 8.0 & \\
\hline High school/university & 6.0 & 2.0 & 8.0 & \multirow{2}{*}{$0.0341^{*}$} \\
\hline Father & 2.0 & 0.0 & 7.5 & \\
\hline Elementary/no education & &
\end{tabular}

Q: interquartiles; ${ }^{*}$ Statistically significant. 
Table 4 - Relationship between caries index and gender, cyanosis and negative behavior.

\begin{tabular}{c|c|c|c|c|c|c|c|c|c}
\hline \multirow{2}{*}{} & \multicolumn{4}{|c|}{ Gender } & \multicolumn{4}{c|}{ Cyanosis } & \multicolumn{3}{c}{ Negative behavior } \\
\cline { 2 - 11 } & $F$ & $M$ & $p$ value & Yes & No & p value & Yes & No & p value \\
\hline$d$ mft index & 5.5 & 5.4 & 0.857 & 6.6 & 4.6 & $0.015^{*}$ & 7.3 & 3.8 & $<0.0001^{*}$ \\
\hline$d$ (decayed) & 3.9 & 4.6 & 0.292 & 5.2 & 3.6 & $0.016^{*}$ & 5.1 & 3.5 & $0.0121^{*}$ \\
\hline$m$ (missing) & 1.5 & 0.7 & 0.053 & 1.4 & 0.8 & 0.194 & 2.1 & 0.2 & $<0.0001^{*}$ \\
\hline$f$ (filled) & 0.08 & 0.1 & 0.852 & 0.0 & 0.2 & 0.187 & 0.1 & 0.09 & 0.938 \\
\hline
\end{tabular}

* Statistically significant.
Table 5 - Relationship between caries index and use of medicines, presence of father and dentist's treatment refusal.

\begin{tabular}{c|c|c|l|l|l|l|l|l|l}
\hline \multirow{2}{*}{} & \multicolumn{3}{|c|}{ Use of medicines } & \multicolumn{3}{c|}{ Presence of father } & \multicolumn{3}{c}{ Dentist's refusal } \\
\cline { 2 - 11 } & Yes & No & $p$ value & Yes & No & p value & Yes & No & p value \\
\hline$d$ mft index & 5.7 & 5.3 & 0.689 & 5.2 & 7.0 & 0.106 & 7.5 & 4.9 & $0.0098^{*}$ \\
\hline$d$ (decayed) & 3.8 & 4.5 & 0.257 & 4.2 & 4.4 & 0.875 & 5.9 & 3.8 & $0.0064^{*}$ \\
\hline$m$ (missing) & 1.7 & 0.7 & $0.0419^{*}$ & 0.8 & 2.5 & $0.007^{*}$ & 1.45 & 0.99 & 0.3946 \\
\hline$f$ (filled) & 0.2 & 0.03 & 0.108 & 0.09 & 0.14 & 0.721 & 0.06 & 0.1 & 0.7451 \\
\hline
\end{tabular}

* Statistically significant.

Mean $\mathrm{dmft}$ score was $5.4(\mathrm{~d}=4.2 ; \mathrm{m}=1.1$; $\mathrm{f}=0.1$ ), and $80.5 \%$ of the children had at least one caries lesion. Tables 4 and 5 show the relationship between caries index and gender, the presence of cyanotic cardiac disease, the occurrence of negative behavior, use of medicine and dental treatment refusal by another dentist. Dmft index and "decayed" component were also greater when there was an association with cyanotic cardiac disease, whereas dmft index and "decayed" and "missing" components were higher in children with a negative behavior. The dmft index and the "decayed" component were also higher in children with a history of dental treatment refusal by another dentist. Daily use of medicine and absence of a father also led to a statistically higher "missing" component.

\section{Discussion}

Even though the importance of good oral health in preventing bacteremia and infective endocarditis is widely known, ${ }^{9,10,12,17,18}$ the majority of studies with heart disease patients of all ages report that the dental health of these subjects is usually poor. , $^{2,45,7,19}$

A high caries index was found in the present study, in contrast with recent data on the whole Brazilian population, in which a mean dmft value of 2.43 was found for a 5 -year-old population in which
$46.6 \%$ were caries free. ${ }^{20}$ This may be related to the high complexity of congenital cardiac disease and the greater health demands made by this medical condition. Previous studies on the prevalence of dental caries in children with congenital heart disease have shown that these children have higher levels of untreated caries. ${ }^{2,3,7,8,21}$ In addition, $21.5 \%$ of parents mentioned that they had experienced a dentist's refusal to treat their child.

The literature has shown that socioeconomic conditions may influence oral health status. ${ }^{14,22,23}$ This may partially explain the elevated caries index found in the population of low educational level. In the present study, $52.8 \%$ of mothers and $45.8 \%$ of fathers had only elementary education, a factor that may contribute to the high caries index. The educational level of parents was up to 8 years of school attendance, meaning no formal education or just elementary school. Our results showed a significant association between higher caries index and a lower educational level of fathers. Tagliaferro et al. ${ }^{14}$ found a higher risk of high caries index in children whose mothers' educational level consisted of no more than 8 years of schooling.

In spite of the evidence supporting the use of human milk and breastfeeding in preterm infants, barriers to their use appear to persist in infants with 
critical cardiac disease. Breastfed infants do not experience periods of oxygen desaturation, and have many others benefits. ${ }^{24}$ Unfortunately, $54.9 \%$ of the children in our study had not been breast-fed, or else their breastfeeding had been interrupted before six months of age.

Although $51.4 \%$ of our study children's parents knew the importance of antibiotic prophylaxis, only $20.1 \%$ understood its purpose. Balmer et al. ${ }^{21}$ found a similar frequency (64\%) of parent awareness of the relationship between oral health and infective endocarditis. The present study found this frequency to be $66 \%$. Understanding the many processes involved in an illness is essential for motivating a change in habits. In this sense, our population is still far from fully comprehending the importance of oral health in patients with congenital heart disease. Fonseca et al. concluded that the most significant barrier to good oral health is often the lack of knowledge. ${ }^{6}$

The population comprising our study was essentially a surgical group, reflecting our hospital's profile (tertiary care, reference cardiology hospital). This aspect could also have contributed to the process of caries development, since the complexity of the underlying cardiac disease may lead parents to underestimate the importance of oral hygiene..$^{2,4}$

Interestingly, children with cyanotic cardiac disease showed a statistically higher caries index, in comparison to those with acyanotic conditions. This could indicate an additional variable in caries pathophysiology, since adequate blood flow is an important aspect of host defense. On the other hand, this could only reflect a negative behavior regarding toothbrushing, or invasive dental procedures resulting from a more complex cardiac condition. ${ }^{4,6,8}$ Unfortunately, most of the children are taken to the dentist when oral disease has already reached a critical point.

There was also a statistically significant association between caries index ( $\mathrm{dmft}$ and "decayed" component) and negative behavior. This may be followed by distressing experiences, such as multiple extractions, leading to a continuum of unpleasant feelings that may adversely affect oral care ${ }^{8}$ and quality of life. ${ }^{6}$

The presence of a father seems to have an important role in children's oral health, insofar as the study found an association between the "missing" component of the caries index and the absence of a father in their lives. In reviewing the literature on the health of children from a one-parent family, the authors of this study found that one-parent children may suffer more from illnesses than children from two-parent families. One-parent families more frequently come from lower social classes and suffer financial hardship. Accordingly, it has been suggested that the children from these families receive a lower standard of care than two-parent children. ${ }^{25}$ Plutzer and Keirse ${ }^{26}$ found that two-year-old children living in one-parent families are twice as likely to experience early childhood caries than children from twoparent families.

The association between the "missing" component of $\mathrm{dmft}$ and the chronic use of medicines is in agreement with previous studies. ${ }^{2,5}$ The use of sucrose as a sweetening agent in liquid medicines, particularly in pediatric practice, could explain this finding.

Our overall results show the severity of the oral health problem in children suffering from cardiac disease in a developing country, and underscore the importance of educating parents about the importance of good oral health.

The authors would like to highlight some limitations to this study. The first is its observational design that does not allow inferences based on causality. Another limitation is its single-institution study design that does not allow extrapolation to other populations.

\section{Conclusion}

Children with congenital heart disease have poor oral health at a very young age. The educational level of fathers, cyanosis, negative behavior, use of daily medicine and a one-parent family seem to influence the caries experience in children with congenital cardiac disease. Education on the importance of dental care is essential to improve oral health in the patients suffering from cardiac disease. 


\section{References}

1. Hoffman JIE, Kaplan S. The incidence of congenital heart disease. J Am Coll Cardiol. 2002 Jun 19;39(12):1890-900.

2. Hallett KB, Radford DJ, Seow WK. Oral health of children with congenital cardiac diseases: a controlled study. Pediatr Dent. 1992 Jul-Aug;14(4):224-30.

3. Al-Shareed M, Angeletou A, Ashley PF, Lucas VS, Whitehead B, Roberts GJ. An investigation of the oral status and reported oral care of children with heart and heart-lungs transplants. Int J Paediatr Dent. 2000 Dec;10(4):298-305.

4. Silva DB, Souza IPR, Cunha MCSA. Knowledge, attitudes and status of oral health in children at risk for infective endocarditis. Int J Paediatr Dent. 2002 Mar;12(2):124-31.

5. Steksén-Blicks C, Rydberg A, Nyman L, Asplund S, Svaberg C. Dental caries experience in children with congenital heart disease: a case-control study. Int J Pediatr Dent. 2004 Mar;14(2):94-100.

6. Fonseca MA, Evans M, Teske D, Thikkurissy S, Amini H. The impact of oral health on the quality of life of young patients with congenital cardiac disease. Cardiol Young. 2009 Jun;19(3):252-6.

7. Franco E, Saunders CP, Roberts GJ, Suwanprasit A. Dental disease, caries related microflora and salivary $\operatorname{Ig} \mathrm{A}$ of children with severe congenital cardiac disease: an epidemiological and oral microbial survey. Pediatr Dent. 1996 MayJun;18(3):228-35.

8. Balmer R, Booras G, Parsons J. The oral health of children considered very high risk for infective endocarditis. Int $\mathrm{J}$ Paediatr Dent. 2010 May;20(3):173-8

9. Wilson W, Taubert KA, Gewitz M, Lockhart PB, Baddour LM, Levison M, et al. Prevention of infective endocarditis. Guidelines from the American Heart Association. J Am Dent Assoc [Internet]. 2008 Jan [cited 2012 Jan 9];139 Suppl 1:3S-24S. Available from: http//jada.ada.org/content/139/ suppl_1/3S.full.pdf+html. Review. Erratum in: J Am Dent Assoc. 2008 Mar; 139(3):253. American Heart Association [homepage on the Internet].

10. Tomás Carmona I, Diz Dios P, Scully C. Efficacy of antibiotic prophylactic regimens for the prevention of bacterial endocarditis of oral origin. J Dent Res. 2007 Dec;86(12):1142-59.

11. Hartzell JD, Torres D, Kim P, Wortmann G. Incidence of bacteremia after routine tooth brushing. Am J Med Sci. 2005 Apr;329(4):178-80.

12. Delahaye F, Harbaoui B, Cart-Regal V, Gevigney G. Recommendations on prophylaxis for infective endocarditis: dramatic changes over the past seven years. Arch Cardiovasc Dis. 2009 Mar;102(3):233-45.
13. Yasny JS, Herlich A. Perioperative dental evaluation. Mt Sinai J Med. 2012 Jan-Feb;79(1):34-45.

14. Tagliaferro EPS, Ambrosano GMB, Meneghim MC, Pereira AC. Risk indicators and risk predictors of dental caries in schoolchildren. J Appl Oral Sci. 2008 Nov-Dec;16(6):408-13.

15. World Health Organization. Oral Health Surveys. Basic Methods [Internet]. 4th ed. Geneva: World Health Organization; 1997 [cited 2012 Jan 13]. Available from: http://new. paho.org/hq/dmdocuments/2009/OH_st_Esurv.pdf.

16. Frankl SN, Shiere FR, Fogels HR. Should the parent remain with the child in the dental operatory? J Dent Child. 1962;29:150-163.

17. Singh J, Straznicky I, Avent M, Gross AN. Antibiotic prophylaxis for endocarditis: time to reconsider. Aust Dent J. 2005 Dec;50(4 Suppl 2):S60-8.

18. Pallasch TJ. Antibiotic prophylaxis: problems in paradise. Dent Clin North Am. 2003 Oct;47(4):665-79.

19. Meurman JH, Qvarnstrom M, Janket SJ, Nuutinen P. Oral health and health behavior in patients referred for open-heart surgery. Oral Surg Oral Med Oral Pathol Oral Radiol Endod. 2003 Mar;95(3):300-7.

20. Ministério da Saúde. Secretaria de Atenção à Saúde. Departamento de Atenção Básica. SB Brasil, pesquisa nacional de saúde bucal 2010 - resultados principais. Brasília (DF): Ministério da Saúde; 2011 [cited 2012 Jan 21]. 92 p. Available from: http://dab.saude.gov.br/CNSB/sbbrasil/arquivos/ projeto_sb2010_relatorio_final.pdf.

21. Balmer R, Bu'Lock FA. The experiences with oral health and dental prevention of children with congenital heart disease. Cardiol Young. 2003 Oct;13(5):439-43.

22. Tasioula V, Balmer R, Parsons J. Dental health and treatment in a group of children with congenital heart disease. Pediatr Dent. 2008 Jul-Aug;30(4):323-8.

23. Krol DM, Nedley MP. Dental caries: state of the science for the most common chronic disease of childhood. Adv Pediatr. 2007;54(1):215-39.

24. Medoff-Cooper B, Naim M, Torowicz D, Mott A. Feeding, growth, and nutrition in children with congenitally malformed hearts. Cardiol Young. 2010 Dec;20 Suppl 3:149-53.

25. Jennings AJ, Sheldon MG. Review of the health of children in one-parent families. J R Coll Gen Pract. 1985 Oct;35(279):478-83.

26. Plutzer K, Keirse MJNC. Incidence and prevention of early childhood caries in one- and two-parent families. Child Care Health Dev. 2011 Jan;37(1):5-10. 